\title{
Validation of Octanoate Breath Test for Measuring Gastric Emptying in Rats
}

\author{
Ingrid Demedts, ${ }^{1}$ Christophe Vanormelingen, ${ }^{1}$ Hubert Van Billoen, ${ }^{2}$ Tim Vanuytsel, ${ }^{1}$ Ricard Farré, ${ }^{1}$ Tatsuhiro Masaoka, \\ Alfons Verbruggen, ${ }^{2}$ Kristien Verbeke, ${ }^{1}$ Pieter Vanden Berghe ${ }^{1}$ and Jan Tack ${ }^{1 *}$ \\ ${ }^{1}$ Translational Research Center for Gastrointestinal Disorders and ${ }^{2}$ Laboratory of Radiopharmacy, University of Leuven, Leuven, Belgium
}

\section{Background/Aims}

Lack of simple and repeatable tests hampers gastric emptying studies in rats. The aim of this study was to adapt the ${ }^{14} \mathrm{C}$-octanoate solid gastric emptying breath test for application in rats, and to validate it against radioscintigraphic method.

\section{Methods}

After ingestion of a meal containing $3 \mathrm{mCi}{ }^{99 \mathrm{~m}} \mathrm{Tc}$ and $2 \mu \mathrm{Ci}{ }^{14} \mathrm{C}$-octanoate, 23 male Wistar rats were placed on a gamma cam era in a airflow container. Scintigraphic images were taken at regular intervals. The amount of ${ }^{14} \mathrm{CO}_{2}$ in a regularly replaced hyamine hydroxide solution, capturing $\mathrm{CO}_{2}$ in the outflow air, was counted using liquid scintillation spectrometry. ${ }^{99 \mathrm{~m}} \mathrm{Tc}$ gastric retention curves and ${ }^{14} \mathrm{CO}_{2}$-excretion curves were fitted to their respective data. Three rats underwent the same procedures after administration of atropine.

\section{Results}

Overall $\mathrm{T}_{\mathrm{r} 10 \%}$ (time at which $10 \%$ of the original amount of ${ }^{99 \mathrm{~m}} \mathrm{Tc}$ remained in the stomach) was $355 \pm 64$ minutes; $\mathrm{T}_{e 90 \%}$ (time at which $90 \%$ of total amount of ${ }^{14} \mathrm{CO}_{2}$ was excreted) was $325 \pm 106$ minutes. Their correlation coefficient was 0.71 , R-square 0.50 and $P<0.005$. $T_{\mathrm{r} / 2}$ ( $50 \%$ of original amount of ${ }^{99 \mathrm{~m}} \mathrm{Tc}$ remained) was $124 \pm 28$ minutes; $\mathrm{T}_{\mathrm{e} 1 / 2}(50 \%$ of total amount of ${ }^{14} \mathrm{CO}_{2}$ excreted) $114 \pm 32$ minutes. Their correlation coefficient was 0.83 with R-square of 0.69 and $P<0.00005$. In 12 immobilized animals correlation was even better: correlation coefficient 0.84 ; R-square 0.71 and $P<0.001$ ( $T_{r 10 \%}$ was $388 \pm 117$ minutes; $T_{e 90 \%} 532 \pm 219$ minutes; $T_{r 1 / 2}$ of $165 \pm 54$ minutes; $T_{e 1 / 2}$ of $175 \pm 67$ minutes). Atropine significantly lengthened all emptying times: $904 \pm 307$ and $1461 \pm 684$ minutes for $\mathrm{T}_{\mathrm{r} 10 \%}$ and $\mathrm{T}_{e 90 \%}$, respectively; and $432 \pm 117$ minutes for $T_{\mathrm{r} / 2}$ and $473 \pm 190$ minutes for $T_{\mathrm{e} 1 / 2}$.

\section{Conclusions}

We adapted and validated the ${ }^{14} \mathrm{C}$-octanoate gastric emptying breath test for application in rats.

(J Neurogastroenterol Motil 2013;19:171-178)

\section{Key Words}

Breath tests; ${ }^{14} \mathrm{C}$-octanoate; Gastric emptying; Rats

Received: November 17, 2012 Revised: January 2, 2013 Accepted: January 9, 2013

(c) This is an Open Access article distributed under the terms of the Creative Commons Attribution Non-Commercial License (http://creativecommons. org/licenses/by-nc/3.0) which permits unrestricted non-commercial use, distribution, and reproduction in any medium, provided the original work is properly cited.

*Correspondence: Jan Tack, MD, PhD

Translational Research Center for Gastrointestinal Disorders, University of Leuven, 3000 Leuven, Belgium Tel: +32-16-34-5761, Fax: +32-16-34-5939, E-mail: jan.tack@med.kuleuven.be

Financial support: This study was supported by a grant from FWO Belgium (Grant No. G.0736.09), and by a Methusalem grant from Leuven University to Jan Tack.

Conflicts of interest: None.

Author contributions: Ingrid Demedts performed experiments, analysed and interpreted data, and wrote manuscript. Christophe Vanormelingen interpreted data and wrote manuscript. Hubert Van Billoen performed experiments, analysed and interpreted data. Tim Vanuytsel, Ricard Farré, Tatsuhiro Masaoka and Alfons Verbruggen interpreted data and reviewed manuscript. Kristien Verbeke analysed and interpreted data, and reviewed manuscript. Pieter Vanden Berghe designed studies and reviewed manuscript.Jan Tack provided funding, designed studies and reviewed manuscript. 


\section{Introduction}

Gastric emptying is a tightly regulated process, which is influenced by a number of physiological (e.g., satiety and stress) and pathophysiological (e.g., autonomous neuropathy, surgery and drugs) processes. Gastric emptying studies are needed for better understanding of these interactions, and are also an important tool in the development of drugs for several gastrointestinal disorders. Small animals like rats or mice are frequently used in pathophysiological and pharmacological studies, but studies of gastric motility are hampered by the lack of an easily applicable and repeatable gastric emptying test for these models.

Numerous approaches have been reported for evaluating gastric emptying in rats. The most frequently used procedure consists of evaluation of marker contents in various gastrointestinal sites after sacrificing the animal. ${ }^{1-4}$ This technique is labor-intensive and requires a large number of animals for each scheduled sampling time point, to assess the temporal evolution of gastric emptying. Other studies used serial or double sampling procedures in which gastric volume was estimated by aspiration of gastric contents. ${ }^{5-7}$ Depending on the technique used, repeated measurements in the same animal are possible both during a single experimental session and over several experimental sessions. However, this approach has several disadvantages. First, the technique can only measure liquid gastric contents. Second, repeated handling of the animal is required for instillation and recovery of the test meal through oral gavage or via an indwelling gastric canula, and handling is known to increase plasma cortisol and catecholamines, ${ }^{8}$ making stress a potentially relevant confounding factor. Third, surgery is required to install an indwelling gastric canula in some of these techniques. Houghton et $\mathrm{al}^{9}$ demonstrated that even minor abdominal surgery caused delayed gastric emptying for up to 2 months after laparotomy. Scintigraphic methods, the gold standard in humans, are also reported in rats. ${ }^{9-11}$ These techniques involve the use of expensive equipment and ingestion of radioactive isotopes. They also require immobilization of the rat, either by mechanical or chemical restraints, both of which can influence gastric emptying. Immobilization is necessary to maintain a constant distance of the marker-meal to the gamma camera, in order to avoid misinterpreting changes in attenuation of the gamma emissions as changes in retention of radioactivity. ${ }^{12}$

The present study was performed to adapt the ${ }^{14} \mathrm{C}$-octanoate solid gastric emptying breath test, ${ }^{13,14}$ for application in rats and to validate it against a radioscintigraphic method. The advantages of a breath test over radioscintigraphy consist in the use of less expensive equipment and in the less strict immobilization requirements. Similar to scintigraphy, the test meal can be solid and mimic the composition of a normal diet; the test is also repeatable. The breath test takes advantage of the characteristics of octanoic acid, an 8-chain fatty acid. ${ }^{15-18}$ This molecule is passively and rapidly absorbed by the intestinal but not the gastric mucosa, transported without prior esterification via the portal vein to the liver and oxidized to ${ }^{14} \mathrm{CO}_{2}$. The rate at which ${ }^{14} \mathrm{CO}_{2}$ is expired, is therefore proportional to the rate of arrival in the intestine.

\section{Materials and Methods}

\section{Test Meal}

The test meal, which was freshly prepared on the day of the test, consisted of $0.5 \mathrm{~g}$ scrambled egg yolk. This was doped with 3 $\mathrm{mCi}{ }^{99} \mathrm{~m}$ Tc-albumin colloid (Ultra Technicow, Malinkrodt Medical, Petten, The Netherlands), $2 \mu \mathrm{Ci}^{14} \mathrm{C}$-octanoic acid, and sodium salt (DuPont, NEN Research, Boston, MA, USA) and then baked. Subsequently, the baked yolk was mixed with $9.5 \mathrm{~g}$ standard rat chow (4352 Muracon G, Nutreco Belgium NV, Gent, Belgium). Tap water (1:1) was added to form a homogenous paste (fat $6.26 \%$, carbohydrates $33.73 \%$, proteins $20.84 \%$ and $1.37 \mathrm{kcal} / \mathrm{g}$ ). The paste was divided in aliquots of $0.5 \mathrm{~g}$. From previous (unpublished) observations we knew that this amount was rapidly ingested by most animals after an overnight fast.

\section{Animals}

Twenty-six male Wistar rats (250-400 g) were housed in wire-mesh bottom cages in a restricted access room with a 12-hour light-dark cycle. Standard laboratory rat chow was available ad libitum until the night before the test, when it was removed. Tap water was freely available at all times, except during the test.

\section{Test Procedures}

\section{Protocol 1: Standard breath test emptying protocol}

After an overnight fast, 10 rats spontaneously ate the $0.5 \mathrm{~g}$ test meal, while 4 rats were given $0.5 \mathrm{~g}$ of the test meal by gavage. Immediately after ingestion of the test meal, the rat was placed in an airtight container through which a continuous airflow $(80 \%$ $\mathrm{N}_{2}$ and $20 \% \mathrm{O}_{2}$ ) of $0.5 \mathrm{~mL} / \mathrm{min}$ was maintained (Fig. 1). The dimensions of the container (diameter $6 \mathrm{~cm}$ and length $23 \mathrm{~cm}$ ) were 


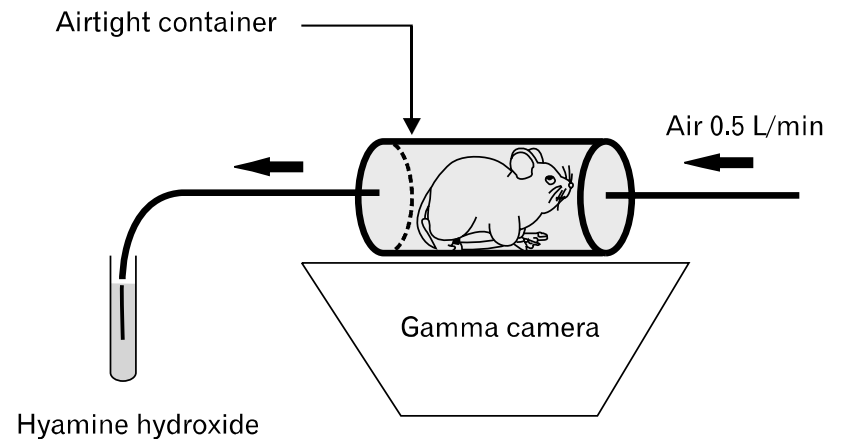

Figure 1. Set-up of the experiment. After food intake, the rat is placed in an airtight container through which a continuous airflow of $0.5 \mathrm{~L} / \mathrm{min}$ is maintained with outgoing air bubbles through a tube containing the $\mathrm{CO}_{2}$-trapper hyamine hydroxide. The airtight container is placed on a gamma camera.

chosen to allow forward and backward movements of the rat whilst keeping the stomach-camera distance relatively constant. The container was placed on a single head gamma camera (Pho/ Gamma IV, Searle, Nuclear Chicago Division, Des Plaines, IL, USA). The gas outflow of the container was bubbled through a tube filled with a solution containing 2 mmol hyamine hydroxide, a $\mathrm{CO}_{2}$-trapper, and thymolphthaleine as indicator. Decoloration of the fluid indicated saturation with $\mathrm{CO}_{2}$; this never occurred with a sampling time of 5 minutes, therefore, all the $\mathrm{CO}_{2}$ expired during this time was captured. Preliminary tests with 2 tubes in series showed that more than 95 percent of $\mathrm{CO}_{2}$ was retained in the first tube; hence only 1 tube was used in the present study. A hyamine hydroxide tube was connected to the container for a period of 5 minutes before the meal, at every 5 minutes during the first half hour and every 15 minutes for the remainder of the test period. After the initial image immediately after ingestion of the test meal, images were obtained at every 5 minutes for the first hour, then every 10 minutes for the following hours depending on the propagation of the meal by visual inspection. The test was ended when no discernible region of interest remained in the gastric area. By this time, ${ }^{14} \mathrm{CO}_{2}$-excretion was tailing off with bulk of it being already past (Fig. 2).

\section{Protocol 2: Immobilization protocol}

To minimize variability in the scintigraphic data due to incomplete immobilization, a second series of tests were performed. After an overnight fast, 8 rats spontaneously ate the $0.5 \mathrm{~g}$ test meal at the same session and 1 rat was given $0.5 \mathrm{~g}$ of the test meal by gavage. Immediately after ingestion of the test meal the rat was placed in a restraining device, which was inserted into the airtight container, while taking care to keep the position of each rat identi-

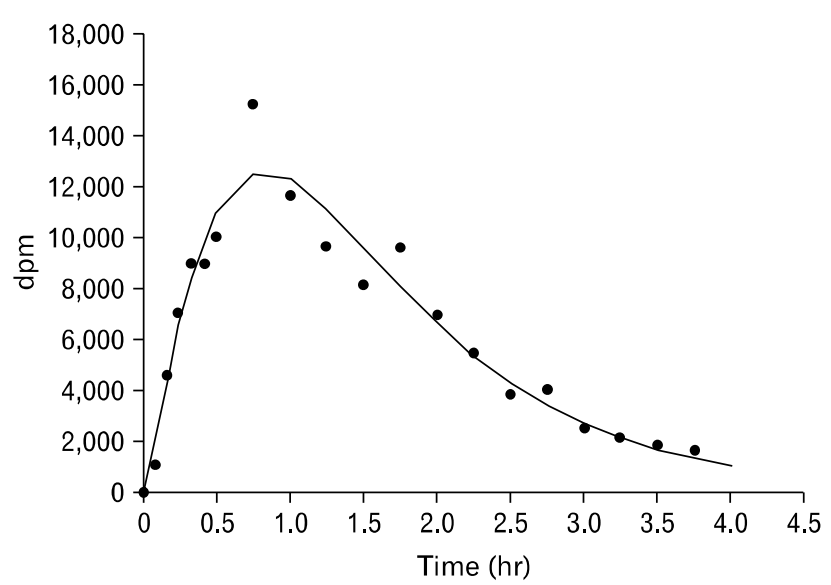

Figure 2. Examples of scintigrafic and breath test curves.

cal in respect to the gamma camera. After an initial image immediately after ingestion of the test meal, images were obtained at every 5 minutes for the first hour, then at every 15 minutes for the remainder of the test period. Once before the test meal and then every 5 minutes during the first half hour and every 15 minutes for the remainder of the test period, the hyamine hydroxide vial was connected to the container for a period of 5 minutes. Again, the test was ended when there was no longer any discernible region of interest in the gastric area.

\section{Protocol 3: Pharmacological intervention}

To investigate the effect of inhibition of cholinergic blockade, 3 rats were given atropine sulphate (Sigma Chemical Company, St. Louis, MO, USA) of $5 \mathrm{mg} / \mathrm{kg}$ intraperitoneally after an overnight fast. Twenty minutes afterwards they spontaneously ate the $0.5 \mathrm{~g}$ test meal. The rest of the procedure was identical to test 2 , except that it was terminated 7 hours after ingestion of the test meal. All procedures were approved by the Animal Care and Use Committee of the university.

\section{Analysis of the ${ }^{99 \mathrm{~m}} \mathrm{Tc}$-albumin Colloid Gastric Retention Curve}

The region of interest was drawn for every image and its amount of radioactivity was measured (Paragon ${ }^{\mathrm{TM}}$, Medasys, Ann Arbor, Michigan, USA). ${ }^{99 \mathrm{~m}} \mathrm{Tc}$ gastric retention curves were fitted to the data, using the following model: $y=1-\left(1-\mathrm{e}^{-a t}\right)^{\beta}$. The $y$ is the fractional dose of radioactivity retained in the stomach at time; $\mathrm{t}$ is the time in minutes; $\alpha$ and $\beta$ are regression estimated constants, with $\alpha$ the gastric emptying rate per minute. ${ }^{19,20}$ From the best fit the following parameters were calculated: $\mathrm{T}_{\mathrm{r} 1 / 2}$ (time at which $50 \%$ of the original amount of ${ }^{99 \mathrm{~m}} \mathrm{Tc}$ remained in the stomach) as $(-1 / \mathrm{k}) \ln \left(1-0.5^{1 / \beta}\right)$; and $\mathrm{T}_{\mathrm{r} 10 \%}$ (time at which $10 \%$ of the original 
amount of ${ }^{99 \mathrm{~m}} \mathrm{Tc}$ remained in the stomach $)$ as $(-1 / \mathrm{k}) \ln \left(1-0.9^{1 / \beta}\right)$.

\section{Analysis of the ${ }^{14} \mathrm{C}$-octanoate Gastric Emptying Breath Test}

After adding $10 \mathrm{~mL}$ of scintillation solution (Hionic Fluor, Packard Instrument Company, Dowers Grove, IL, USA), the amount of ${ }^{14} \mathrm{CO}_{2}$ in the solution was counted using a liquid scintillation spectrometer system (model 2450 Packard; Packard Instrument Company). ${ }^{14} \mathrm{CO}_{2}$ excretion curves were fitted to the data, using models given by the following formulas: $\mathrm{y}=$ $\mathrm{mk} \beta \mathrm{e}^{-\mathrm{kt}}\left(1-\mathrm{e}^{-\mathrm{kt}}\right)^{\beta-1}$ or $\mathrm{y}=\mathrm{at}{ }^{\mathrm{b}} \mathrm{e}^{\text {-ct }}$. ${ }^{13,14}$ The $\mathrm{y}$ is the ${ }^{14} \mathrm{CO}_{2}$ excretion in breath per hour; $t$ is the time in hours; $\mathrm{m}, \mathrm{k}, \beta$, a, b and $\mathrm{c}$ are regression estimated constants, with $\mathrm{m}$ the total amount of ${ }^{14} \mathrm{CO}_{2}$ recovered when time is infinite. From the best fit the following parameters were calculated: $\mathrm{T}_{\mathrm{e} 1 / 2}$ (time at which $50 \%$ of the total amount of ${ }^{14} \mathrm{CO}_{2}$ was excreted $)$ as $(-1 / \mathrm{k}) \ln \left(1-0.5^{1 / \beta}\right) \times 60 ; \mathrm{T}_{\mathrm{e} 90 \%}$ (time at which $90 \%$ of the total amount of ${ }^{14} \mathrm{CO}_{2}$ was excreted) as $(-1 / \mathrm{k}) \ln \left(1-0.91^{1 / \beta}\right) \times 60$; and gastric emptying coefficient (GEC, global index for the gastric emptying rate) as $\ln (a)$. The lag phase has been defined in different ways over time: originally it represented the initial delay in gastric emptying of solids as compared to liquids. Later, its value was determined as the point of inflection of the cumulative excretion curve, corresponding to the time when the peak of the excretion curve was reached or even as the time at which $10 \%$ of the total amount of ${ }^{14} \mathrm{CO}_{2}$ was excreted. ${ }^{13,14,19-22}$

A

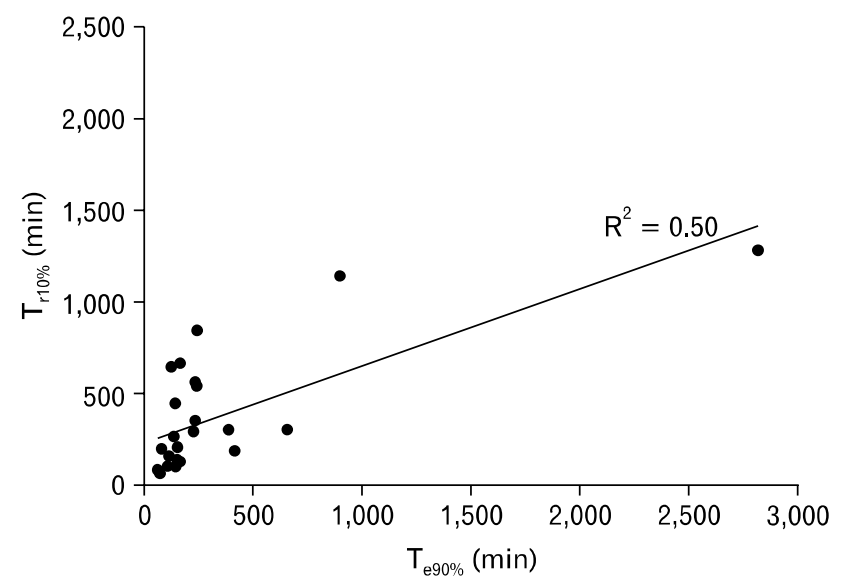

\section{Statistical Methods}

$\mathrm{T}_{\mathrm{r} 10 \%}, \mathrm{~T}_{\mathrm{e} 90 \%,} \mathrm{~T}_{\mathrm{r} 1 / 2}, \mathrm{~T}_{\mathrm{e} 1 / 2}$ and GEC were calculated (mean \pm SEM). Regression analysis (correlation coefficient, R-square and $P$-value) between $\mathrm{T}_{\mathrm{r} 10 \%}$ and $\mathrm{T}_{\mathrm{e} 90 \%}$ was performed on the pooled data of all 26 rats and on the immobilized and free group separately. According to the method proposed by Bland and Altman $^{23,24}$ for determination of the limits of agreement, 2 plots for visual analysis were made: the breath test results against the scintigraphic ones and the difference in measurements against the average of the 2 measurements. The same procedures were followed for $\mathrm{T}_{\mathrm{r} 1 / 2}$ and $\mathrm{T}_{\mathrm{e} 1 / 2}$. Regression analysis was also performed between $T_{\mathrm{r} 1 / 2}$ and GEC; but no limits of agreement could be determined since the units of measurement were different (minutes versus a mathematical parameter). To study the effects of immobilization and gavage we performed $t$ tests of all emptying parameters between spontaneously fed free and immobilized rats and between spontaneous and gavage fed animals. We also performed $t$ tests between atropine pretreated and not pretreated immobilized animals.

\section{Results}

\section{Pooled Data Scintigraphic $\mathrm{T}_{\mathrm{r} 10 \%}$ and Breath Test $\mathrm{T}_{\mathrm{e} 90 \%}$}

For all 26 rats, the scintigraphic $\mathrm{T}_{\mathrm{r} 10 \%}$ was $355 \pm 64$ minutes; $\mathrm{T}_{\mathrm{e} 90 \%}$ for the breath test was $325 \pm 106$ minutes. Their correlation

B

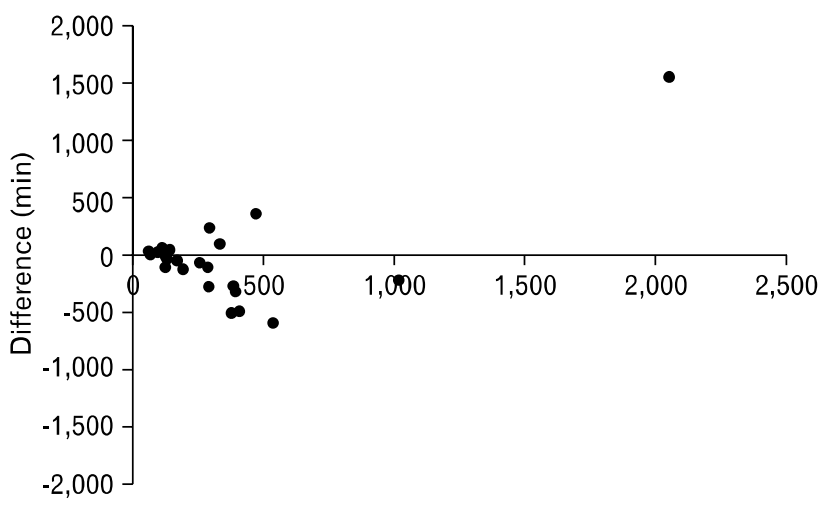

Average (min)

Figure 3. The left panel (A) depicts correlation $\mathrm{T}_{\mathrm{e} 90 \%}$ (time at which $90 \%$ of the total amount of ${ }^{14} \mathrm{CO}_{2}$ was excreted) and $\mathrm{T}_{\mathrm{r} 10 \%}$ (time at which $10 \%$ of the original amount of ${ }^{99 \mathrm{~m}} \mathrm{Tc}$ remained in the stomach). The right panel (B) plots the difference in measurements against the average of 2 measurements $\left(\mathrm{T}_{\mathrm{e} 90 \%}\right.$ and $\mathrm{T}_{\mathrm{r} 10 \%)}$. 
coefficient was 0.71 ; R-square 0.50 and $P<0.0005$ (Fig. 3). We also plotted the difference in measurements against the average of the 2 measurements, according to the method proposed by Bland and Altman (Fig. 3). ${ }^{23,24}$ This figure shows the scatter of differences increasing as the average increases. As a consequence of this, the limits of agreement would be wider apart than necessary for the smaller values and narrower than they should be for larger values; we did not perform a formal analysis on the limits of agreement. In the 14 free moving rats from the first test, the scintigraphic $\mathrm{T}_{\mathrm{r} 10 \%}$ was $328 \pm 68$ minutes; $\mathrm{T}_{\mathrm{e} 90 \%}$ for the breath test was $147 \pm 18$ minutes. Their correlation coefficient was 0.59 ; R-square 0.35 and $P<0.05$. The 12 immobilized rats from test 2 had a scintigraphic $\mathrm{T}_{\mathrm{r} 10 \%}$ of $388 \pm 117$ minutes; $\mathrm{T}_{\mathrm{e} 90 \%}$ for the breath test was $532 \pm 219$ minutes. Their correlation coefficient was 0.84 ; R-square 0.71 and $P<0.001$. The large variability in these rats was caused by much higher values of emptying times after atropine (cfr. infra): $904 \pm 307$ versus $216 \pm 49$ minutes and $1461 \pm 684$ versus $223 \pm 35$ minutes for $\mathrm{T}_{\mathrm{r} 10 \%}$ and $\mathrm{T}_{\mathrm{e} 90 \%}$, respectively.

\section{Pooled Data of Scintigraphic $T_{r 1 / 2}$ and Breath Test $\mathrm{T}_{\mathrm{e} 1 / 2}$}

For all 26 rats, the scintigraphic $\mathrm{T}_{\mathrm{r} 1 / 2}$ was $124 \pm 28$ minutes; $\mathrm{T}_{\mathrm{e} 1 / 2}$ for the breath test was $114 \pm 32$ minutes. Their correlation coefficient was 0.83 ; R-square 0.69 and $P<0.00005$ (Fig. 4). Again, the plot of difference in measurements against the average of 2 measurements showed an increased scatter of differences with increasing averages: no formal analysis of the limits of agree- ment was attempted (Fig. 4). In the 14 free rats from the first test, the scintigraphic $\mathrm{T}_{\mathrm{r} 1 / 2}$ was $89 \pm 19$ minutes; $\mathrm{T}_{\mathrm{e} 1 / 2}$ for the breath test was $61 \pm 8$ minutes. Their correlation coefficient was 0.79 ; R-square 0.62 and $P<0.001$. The 12 immobilized rats from test 2 had a scintigraphic $\mathrm{T}_{\mathrm{r} 1 / 2}$ of $165 \pm 54$ minutes; $\mathrm{T}_{\mathrm{e} 1 / 2}$ for the breath test was $175 \pm 67$ minutes. Their correlation coefficient was 0.84 ; R-square 0.71 and $P<0.001$. Again, the large variability was caused by the much higher values after atropine (cfr. infra): $432 \pm 117$ versus $76 \pm 17$ minutes for $T_{\mathrm{r} 1 / 2}$ and $473 \pm$ 190 versus $76 \pm 14$ minutes for $\mathrm{T}_{\mathrm{e} 1 / 2}$, respectively.

\section{Scintigraphic $T_{r 1 / 2}$ and Breath Test Gastric Emptying Coefficient}

GEC in immobilized rats was $7.23 \pm 0.28$ (Fig. 5). It showed a comparable, though inverse, correlation to the scintigraphic $\mathrm{T}_{\mathrm{r} 1 / 2}$ as $\mathrm{T}_{\mathrm{e} 1 / 2}$ (correlation coefficient of -0.83, R-square of 0.69 and $P<0.001)$. No correlation could be shown in the pooled data or in the free rats.

\section{Effect of Immobilization}

Parameters from 9 spontaneously fed and free-moving animals were compared by unpaired t-test with parameters from 8 spontaneously fed rats, immobilized in a restraining device. Although values tended to be higher in immobilized animals, significance was only reached with the breath test $\mathrm{T}_{\mathrm{e} 90 \%}$ (Table 1).

\section{Effect of Gavage}

Parameters from 17 spontaneously and 5 gavage fed rats
A

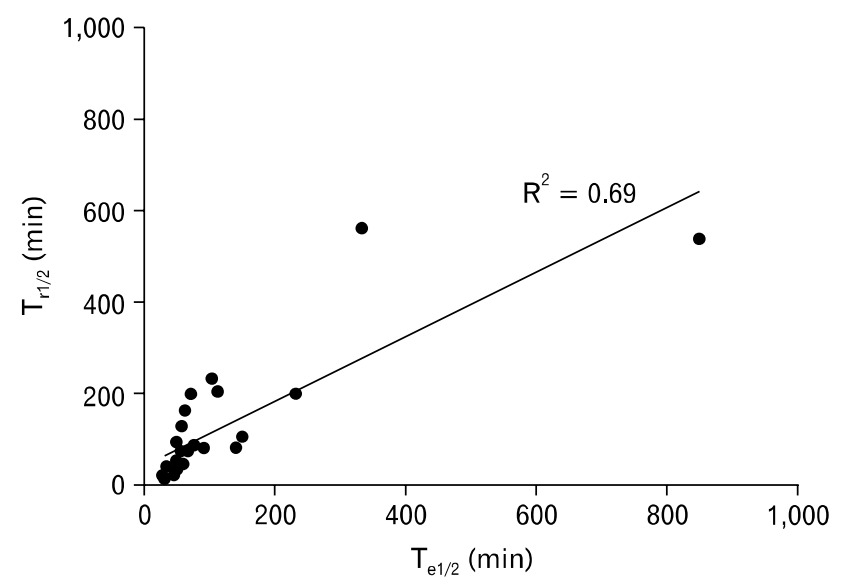

B

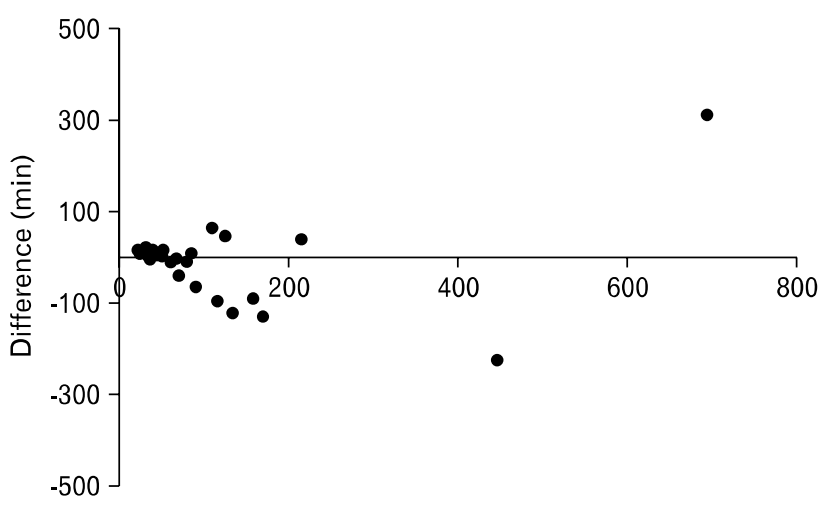

Average (min)

Figure 4. The left panel depicts the correlation between $\mathrm{T}_{\mathrm{e} 1 / 2}$ (time at which $50 \%$ of the total amount of ${ }^{14} \mathrm{CO}_{2}$ was excreted) and $\mathrm{T}_{\mathrm{r} 1 / 2}$ (time at which $50 \%$ of the original amount of ${ }^{99 \mathrm{~m}} \mathrm{Tc}$ remained in the stomach). The right pannel plots the difference in the measurements of $\mathrm{T}_{\mathrm{e} 1 / 2}$ and $\mathrm{T}_{\mathrm{r} 1 / 2}$ against the average of the 2 measurements. 


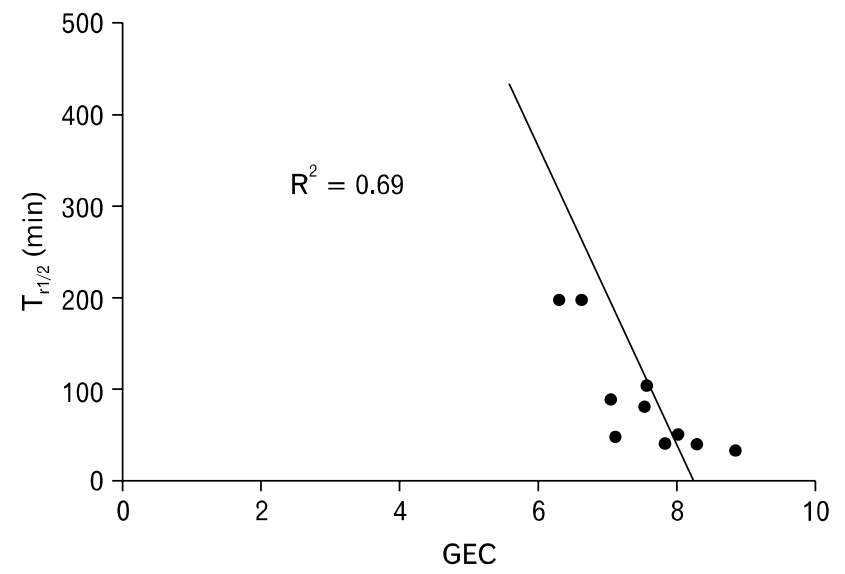

Figure 5. Correlation gastric emptying coefficient and $\mathrm{T}_{\mathrm{r} 1 / 2}$ (time at which $50 \%$ of the original amount of ${ }^{99 \mathrm{~m}} \mathrm{Tc}$ remained in the stomach) in immobilized rats. GEC, gastric emptying coefficient.

Table 1. Free Versus Immobilized Animals

\begin{tabular}{lccc}
\hline & $\begin{array}{c}\text { Free } \\
\text { animals }\end{array}$ & $\begin{array}{c}\text { Immobilized } \\
\text { animals }\end{array}$ & $P$-value \\
\hline Scintigrafic data (min) & & & \\
$\mathrm{T}_{\mathrm{r} 1 / 2}$ & $48 \pm 9$ & $74 \pm 20$ & $\mathrm{NS}$ \\
$\mathrm{T}_{\mathrm{r} 10 \%}$ & $204 \pm 60$ & $200 \pm 52$ & $\mathrm{NS}$ \\
Breath test data (min) & & & \\
$\mathrm{T}_{\mathrm{e} 1 / 2}$ & $47 \pm 6$ & $76 \pm 15$ & $\mathrm{NS}$ \\
$\mathrm{T}_{\mathrm{e} 90 \%}$ & $119 \pm 16$ & $221 \pm 40$ & $<0.05$
\end{tabular}

$\mathrm{T}_{\mathrm{r} 1 / 2}$, time at which $50 \%$ of the original amount of ${ }^{99 \mathrm{~m}} \mathrm{Tc}$ remained in the stomach; $\mathrm{T}_{\mathrm{r} 10 \%}$, time at which $10 \%$ of the original amount of ${ }^{99 \mathrm{~m}} \mathrm{Tc}$ remained in the stomach; $\mathrm{T}_{\mathrm{e} 1 / 2}$, time at which $50 \%$ of the total amount of ${ }^{14} \mathrm{CO}_{2}$ was excreted; $\mathrm{T}_{\mathrm{e} 90 \%}$, time at which $90 \%$ of the total amount of ${ }^{14} \mathrm{CO}_{2}$ was excreted.

were compared by unpaired $t$ tests. Values were higher after gavage, although significance was only reached in the scintigraphic data (Table 2). Including only data from free-moving rats did not alter the significance levels.

\section{Effect of Atropine}

Unpaired $t$ tests were performed on 11 spontaneously fed immobilized animals, 3 of whom pretreated with atropine. There was a significant and marked lengthening of all emptying parameters (Table 3).

\section{Discussion}

In this study we adapted the ${ }^{14} \mathrm{C}$-octanoate breath test for use in rats. When compared to the human test, one of the major dif-
Table 2. Spontaneously Versus Gavage Fed Animals

\begin{tabular}{lccc}
\hline & $\begin{array}{c}\text { Spontaneously } \\
\text { fed animals }\end{array}$ & $\begin{array}{c}\text { Gavage } \\
\text { fed animals }\end{array}$ & $P$-value \\
\hline $\begin{array}{ccc}\text { Scintigrafic data (min) } \\
\mathrm{T}_{\mathrm{r} 1 / 2}\end{array}$ & $60 \pm 11$ & $132 \pm 25$ & $<0.01$ \\
$\mathrm{~T}_{\mathrm{r} 10 \%}$ & $202 \pm 39$ & $450 \pm 72$ & $<0.01$ \\
Breath test data (min) & & & \\
$\mathrm{T}_{\mathrm{e} 1 / 2}$ & $61 \pm 8$ & $76 \pm 9$ & $\mathrm{NS}$ \\
$\mathrm{T}_{\mathrm{e} 90 \%}$ & $167 \pm 24$ & $182 \pm 22$ & $\mathrm{NS}$ \\
\hline
\end{tabular}

$\mathrm{T}_{\mathrm{r} 1 / 2}$, time at which $50 \%$ of the original amount of ${ }^{99 \mathrm{~m}} \mathrm{Tc}$ remained in the stomach; $\mathrm{T}_{\mathrm{r} 10 \%}$, time at which $10 \%$ of the original amount of ${ }^{99 \mathrm{~m}} \mathrm{Tc}$ remained in the stomach; $\mathrm{T}_{\mathrm{e} 1 / 2}$, time at which $50 \%$ of the total amount of ${ }^{14} \mathrm{CO}_{2}$ was excreted; $\mathrm{T}_{\mathrm{e} 90 \%}$, time at which $90 \%$ of the total amount of ${ }^{14} \mathrm{CO}_{2}$ was excreted.

Table 3. With and Without Atropine

\begin{tabular}{lrrl}
\hline & Without atropine & After atropine & $P$-value \\
\hline Scintigrafic data (min) & & & \\
$\mathrm{T}_{\mathrm{r} 1 / 2}$ & $74 \pm 20$ & $432 \pm 117$ & $<0.001$ \\
$\mathrm{~T}_{\mathrm{r} 10 \%}$ & $199 \pm 52$ & $904 \pm 307$ & $<0.01$ \\
Breath test data (min) & & & \\
$\mathrm{T}_{\mathrm{e} 1 / 2}$ & $76 \pm 15$ & $473 \pm 190$ & $<0.01$ \\
$\mathrm{~T}_{\mathrm{e} 90 \%}$ & $221 \pm 40$ & $1461 \pm 684$ & $<0.05$ \\
\hline
\end{tabular}

$\mathrm{T}_{\mathrm{r} 1 / 2}$, time at which $50 \%$ of the original amount of ${ }^{99 \mathrm{~m}} \mathrm{Tc}$ remained in the stomach; $\mathrm{T}_{\mathrm{r} 10 \%}$, time at which $10 \%$ of the original amount of ${ }^{99 \mathrm{~m}} \mathrm{Tc}$ remained in the stomach; $\mathrm{T}_{\mathrm{e} 1 / 2}$, time at which $50 \%$ of the total amount of ${ }^{14} \mathrm{CO}_{2}$ was excreted; $\mathrm{T}_{\mathrm{e} 90 \%}$, time at which $90 \%$ of the total amount of ${ }^{14} \mathrm{CO}_{2}$ was excreted.

ferences is the fact that in each sample, we captured all $\mathrm{CO}_{2}$ produced during the sampling period. This means that during the first half hour of the test, when the rapid rise to the peak excretion occurs, all excreted ${ }^{14} \mathrm{CO}_{2}$ is captured (sampling during $5 \mathrm{mi}$ nutes, with a new tube for every 5 minutes). Also, we did not express the ${ }^{14} \mathrm{CO}_{2}$ excretion as a percentage of either the administered or the total recovered amount, but as actual amount captured during the sampling period. Furthermore, since we used ${ }^{14} \mathrm{C}$ rather than ${ }^{13} \mathrm{C}$ as a marker, we were certain that all excreted ${ }^{14} \mathrm{CO}_{2}$ originated from the administered test meal itself.

The ${ }^{14} \mathrm{C}$-octanoate breath test can be used to measure gastric emptying because the postgastric processes of intestinal absorption, transport and metabolism are thought to be constant. In humans, inter-individual but not intra-individual variations were demonstrated in healthy volunteers. ${ }^{20,21}$ However, these volunteers included both males and females and the age difference was as much as 51 years between the oldest and youngest volunteer. In our study, as indeed in most animal studies, same sex (usually male) and similar weight animals from the same genetic pool were used. These animals had all been living under the same condi- 
tions. Therefore inter-individual variations of octanoate metabolism are likely to be smaller.

We found a good correlation between breath test and scintigraphic emptying parameters. As expected, this correlation was better for immobilized than for free-moving rats, probably attributable to the variations in meal-to-camera distance in free-moving rats.

The differences between results from both tests seem to increase towards the higher values. This probably reflects amplification of errors. As Choi et $\mathrm{al}^{21,22}$ pointed out in their human studies, if the length of the collecting period is too short, the estimate of the regression parameter is less accurate, leading to overestimation of breath test, emptying times. However, even if the optimal length of testing has not been established, for each individual test, it can be postulated that the test period would be long enough if its cumulative excretion curve reached a plateau instead of still being in the ascending slope. The plateau in the cumulative excretion curve corresponds to the tailing off of the descending slope towards the horizontal axis in the excretion curve (Fig. 2). For most of the tested rats, this tailing off was present with the atropine treated rats being the exception.

Scintigraphic emptying times in our studies were as long as or longer than their breath test counterparts. This may be due to positioning of the rat: when the stomach region of interest and first part of the duodenum overlap, the initial stages of gastric emptying are invisible on the gamma camera images while ${ }^{14} \mathrm{CO}_{2}$ is already expired. Testing this hypothesis requires a dual head gamma camera, but this is not available for animal studies in our center. As a consequence, we were not able to calculate a correcting factor for the breath test emptying times, corresponding to the time needed for post-gastric emptying processing of ${ }^{14} \mathrm{C}$-octanoic acid. Thus, it must be stressed that although there is a good correlation between scintigraphic and breath test parameters, their values are not interchangeable.

We also demonstrated that gastric emptying of solids, measured by the breath test, was much slower after administration of the anticholinergic agent atropine. The atropine dose we used was similar to previous studies, ${ }^{25,26}$ and was half the dose reported to have a full blocking effect in studies of heart rate variability. ${ }^{27}$ Immobilization and gavage tended to be associated with longer emptying times, although significance was never reached in the breath test, possibly due to the relatively low number of animals studied, especially in the gavage group.

In conclusion, we adapted and validated the ${ }^{14} \mathrm{C}$-octanoate solid gastric emptying breath test for application in rats. The availability of this test offers perspectives or repeated pharmacological and pathophysiological studies of gastric emptying in rats.

\section{References}

1. Droppleman DA, Gregory RL, Alphin RS. A simplified method for assessing drug effects on gastric emptying in rats. J Pharmacol Methods 1980;4:227-230.

2. Scarpignato C, Capovilla T, Bertaccini G. Action of caerulein on gastric emptying of the conscious rat. Arch Int Pharmacodyn Ther 1980;246:286-294.

3. Luck MS, White JC, Bass P. Gastrointestinal transit is not impaired by regional loss of myenteric neurons in rat jejunum. Am J Physiol 1993;265(4 Pt 1):G654-G659.

4. Chang FY, Lee SD, Yeh GH, Wang PS. Influence of blood glucose levels on rat liquid gastric emptying. Dig Dis Sci 1996;41:528-532.

5. Granneman JG, Stricker EM. Food intake and gastric emptying in rats with streptozotocin-induced diabetes. Am J Physiol 1984;247(6 Pt 2):R1054-R1061.

6. Moran TH, McHugh PR. Cholecystokinin suppresses food intake by inhibiting gastric emptying. Am J Physiol 1982;242:R491-R497.

7. Conover KL, Weingarten HP, Collins SM. A procedure for within-trial repeated measurement of gastric emptying in the rat. Physiol Behav 1987;39:303-308.

8. Kvetnansky R, Sun CL, Lake CR, Thoa N, Torda T, Kopin IJ. Effect of handling and forced immobilization on rat plasma levels of epinephrine, norepinephrine, and dopamine-beta-hydroxylase. Endocrinology 1978;103:1868-1874.

9. Houghton AD, Liepins P, Mason RC, Clarke SM. The effect of minor gastric surgery on gastric emptying in the rat. Nucl Med Commun 1991;12:965-971.

10. Ruytjens I, Thomforde GM, Camilleri M, Chapman NJ. Effect of chemical sympathectomy on scintigraphic gastric and small bowel transit in the rat. J Auton Nerv Syst 1992;39:111-117.

11. Stein J, Zeuzem S, Uphoff K, Laube H. Effects of prostaglandins and indomethacin on gastric emptying in the rat. Prostaglandins 1994;47:31-40.

12. Tothill $\mathrm{P}, \mathrm{McL}$ oughlin GP, Heading RC. Techniques and errors in scintigraphic measurements of gastric emptying. J Nucl Med 1978; 9:256-261.

13. Maes BD, Ghoos YF, Geypens BJ, et al. Combined carbon-3lycine/carbon-14-octanoic acid breath test to monitor gastric emptying rates of liquids and solids. J Nucl Med 1994;35:824-831.

14. Ghoos YF, Maes BD, Geypens BJ, et al. Measurement of gastric emptying rate of solids by means of a carbon-labeled octanoic acid breath test. Gastroenterology 1993;104:1640-1647.

15. Bach AC, Babayan VK. Medium-chain triglycerides: an update. Am J Clin Nutr 1982;36:950-962.

16. Clark SB, Holt PR. Inhibition of steady-state intestinal absorption of long-chain triglyceride by medium-chain triglyceride in the unanesthetized rat. J Clin Invest 1969;48:2235-2243.

17. Fritz IB. Carnitine and its role in fatty acid metabolism. Adv Lipid Res 1963;1:285-334.

18. Scheig R, Klatskin G. Hepatic metabolism of $1-{ }^{14} \mathrm{C}$ octanoic and $1-{ }^{14} \mathrm{C}$ palmitic acids. J Am Oil Chem Soc 1968;45:31-33. 
19. Siegel JA, Urbain JL, Adler LP, et al. Biphasic nature of gastric emptying. Gut 1988;29:85-89.

20. Urbain JL, Siegel JA, Mortelmans L, van Cutsem E, van den Maegdenbergh V, de Roo M. Effect of solid-meal caloric content on gastric emptying kinetics of solids and liquids. Nuklearmedizin 1989;28:120-123.

21. Choi MG, Camilleri M, Burton DD, Zinsmeister AR, Forstrom LA, Nair KS. $\left[{ }^{13} \mathrm{C}\right]$ octanoic acid breath test for gastric emptying of solids: accuracy, reproducibility, and comparison with scintigraphy. Gastroenterology 1997;112:1155-1162.

22. Choi MG, Camilleri M, Burton DD, Zinsmeister AR, Forstrom LA, Nair KS. Reproducibility and simplification of ${ }^{13} \mathrm{C}$-octanoic acid breath test for gastric emptying of solids. Am J Gastroenterol 1998;93:92-98.

23. Bland JM, Altman DG. Statistical methods for assessing agreement between two methods of clinical measurement. Lancet 1986;1: 307-310.

24. Bland JM, Altman DG. Comparing methods of measurement: why plotting difference against standard method is misleading. Lancet 1995;346:1085-1087.

25. Salim AS. The role of vagal adrenergic activity in the mechanism of gastric acid secretion after pylorus-ligation in the rat. J Pharm Pharmacol 1989;41:566-568.

26. Cho $\mathrm{CH}$, Ogle $\mathrm{CW}$. Cholinoceptor blockers protect against ethanol-induced gastric mucosal damage in rats. Pharmacology 1991; 3:304-309.

27. Hicks KK, Seifen E, Stimers JR, Kennedy RH. Effects of streptozotocin-induced diabetes on heart rate, blood pressure and cardiac autonomic nervous control. J Auton Nerv Syst 1998;69:21-30. 